\title{
The most oligotrophic subtropical zones of the global ocean: similarities and differences in terms of chlorophyll and yellow substance
}

\author{
A. Morel, H. Claustre, and B. Gentili \\ Université Pierre et Marie Curie (Paris-6), Laboratoire d'Océanographie de Villefranche, 06238 Villefranche-sur-mer, \\ CEDEX, France
}

CNRS-UMR 7093, Laboratoire d'Océanographie de Villefranche, 06238 Villefranche-sur-mer, CEDEX, France

Received: 17 June 2010 - Published in Biogeosciences Discuss.: 1 July 2010

Revised: 6 October 2010 - Accepted: 8 October 2010 - Published: 14 October 2010

\begin{abstract}
The cores of the subtropical anticyclonic gyres are characterized by their oligotrophic status and minimal chlorophyll concentration, compared to that of the whole ocean. These zones are unambiguously detected by space borne ocean color sensors thanks to their typical spectral reflectance, which is that of extremely clear and deep blue waters. Not only the low chlorophyll (denoted [Chl]) level, but also a reduced amount of colored dissolved organic matter (CDOM or "yellow substance") account for this clarity. The oligotrophic waters of the North and South Pacific gyres, the North and South Atlantic gyres, and the South Indian gyre have been comparatively studied with respect to both [Chl] and CDOM contents, by using 10-year data (19982007) of the Sea-viewing Wide field-of-view Sensor (SeaWiFS, NASA). Albeit similar these oligotrophic zones are not identical regarding their [Chl] and CDOM contents, as well as their seasonal cycles. According to the zone, the averaged [Chl] value varies from 0.026 to $0.059 \mathrm{mg} \mathrm{m}^{-3}$, whereas the $a_{\mathrm{y}}(443)$ average (the absorption coefficient due to $\mathrm{CDOM}$ at $443 \mathrm{~nm}$ ) is between 0.0033 and $0.0072 \mathrm{~m}^{-1}$. The CDOM-to-[Chl] relative proportions also differ between the zones. The clearest waters, corresponding to the lowest [Chl] and CDOM concentrations, are found near Easter Island and near Mariana Islands in the western part of the North Pacific Ocean. In spite of its low [Chl], the Sargasso Sea presents the highest CDOM content amongst the six zones studied. Except in the North Pacific gyre (near Mariana and south of Hawaii islands), a conspicuous seasonality appears to be the rule in the other 4 gyres and affects both [Chl] and CDOM; both quantities vary in a ratio
\end{abstract}

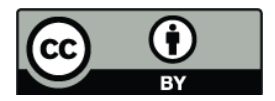

Correspondence to: A. Morel (morel@obs-vlfr.fr) of about 2 (maximum-to-minimum). Coinciding [Chl] and CDOM peaks occur just after the local winter solstice, which is also the period of the maximal mixed layer depth in these latitudes. It is hypothesized that the vertical transport of unbleached CDOM from the subthermocline layers is the main process enhancing the CDOM concentration within the upper layer in winter. In summer, the CDOM experiences its minimum which is delayed with respect to the [Chl] minimum; apparently, the solar photo-bleaching of CDOM is a slower process than the post-bloom algal Chl decay. Where they exist, the seasonal cycles are repeated without notable change from year to year. Long term $(10 \mathrm{y})$ trends have not been detected in these zones. These oligotrophic gyres can conveniently be used for in-flight calibration and comparison of ocean color sensors, provided that their marked seasonal variations are accounted for.

\section{Introduction}

Waters extremely transparent to visible and near ultraviolet solar radiation were found (Morel et al., 2007a, b) in the vicinity of Easter Island within the South Pacific anticyclonic gyre during the BIOSOPE cruise (BIogeochemistry and Optics SOuthPacific Experiment; Claustre et al., 2008). The hyperoligotrophic waters of this gyre are perhaps the "clearest" natural waters in the world ocean. Such an extreme clarity primarily results from the very low level of the phytoplanktonic biomass; indeed, the chlorophyll concentration determined in the upper layer was below $0.03 \mathrm{mg} \mathrm{m}^{-3}$ (in November 2004; see Ras et al., 2008). The exceptional transparency within this oceanic water body also originates from the extremely low level of chromophoric dissolved organic

Published by Copernicus Publications on behalf of the European Geosciences Union. 

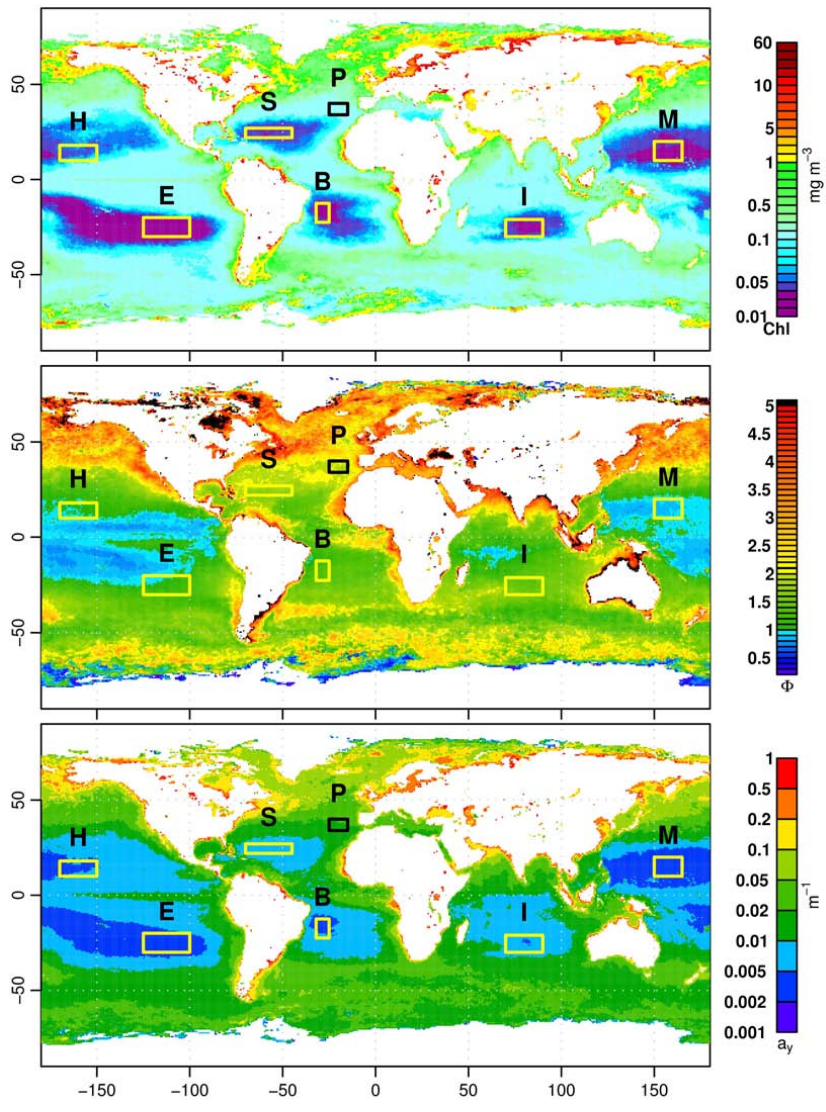

Fig. 1. Annual composite (year 2006) of SeaWiFS data for the global ocean. Upper panel: chlorophyll concentration, [Chl] $\left(\mathrm{mg} \mathrm{m}^{-3}\right)$; middle panel: chromophoric dissolved matter index, $\Phi$ (dimensionless). Both these quantities are provided and distributed by NASA. Lower panel: map of the absorption coefficient at $443 \mathrm{~nm}, a_{\mathrm{y}}\left(\mathrm{m}^{-1}\right)$ of the chromophoric dissolved organic matter, CDOM, computed from [Chl] and $\Phi$ via Eq. (1). Each panel has its own color scale. The (yellow) boxes superimposed on the maps show the oligotrophic zones selected for the present study (see also Table 1 for the exact locations and meaning of the identifiers). The black box in a mesotrophic zone off Portugal (P) is selected for a comparison (see text).

material, CDOM (or "yellow substance", or "Gelbstoff"), as attested by the particularly low values of the attenuation coefficient for downward irradiance in the ultraviolet spectral domain (Morel et al., 2007a; Swan et al., 2009), and also attested by spectroscopic determinations (Bricaud et al., 2010). The special clarity of these waters results in a deep blue color due to the reflectance enhancement in the blue, violet, and UV parts of the spectrum. Space borne Ocean Color sensors are able to detect this enhancement. The recurrent detection from space of a huge "blue hole" denoting a hyperoligotrophic system within the South Pacific gyre was largely at the origin of the BIOSOPE project (Claustre and Maritorena, 2003).

Of course, the question arises about the possible occurrence of similar situations in other parts of the world ocean, not only in terms of algal concentration, but also in terms of yellow substance content. Other subtropical gyres also characterized by anticyclonic circulation, downwelling, and thicker thermoclines, are obvious candidates, since the depressed nutricline limits the algal development and subsequent biological/biochemical processes. These extensive oligotrophic gyres are well known in both hemispheres within the subtropical Atlantic and Pacific oceans (see e.g., Sverdrup et al., 1963; Tomczak and Godfrey, 1994). The south Indian ocean is also the seat of a subtropical anticyclonic system, while in the northern Indian ocean the monsoon regime impedes the regular development of such a similar feature. These desert oceanic areas have unambiguously been detected by ocean color sensors; their huge extension, and their chlorophyll concentration have been documented and monitored (see e.g., McClain et al., 2004; Polovina et al., 2008). Indeed, while the biological activity is comparatively small in these areas, their vast size makes their contribution to the global productivity and biogeochemistry definitely significant (see e.g., Antoine et al., 1996).

These ultramarine oceanic zones were also selected as offering wide and homogeneous targets allowing in-flight calibration of space ocean color sensors to be performed via the Rayleigh scattering calibration method (Fougnie et al., 2002). In this study, based on Sea-viewing Wide Fieldof-view Sensor (SeaWiFS) data, the low chlorophyll level (thereafter denoted [Chl]) within several gyres was confirmed and documented. No attempt, however, was made to comparatively assess the CDOM content. Yet, some years later, actually when the "GSM" algorithm (Siegel et al., 2002,2005 b) was applied to remotely sensed ocean color data, relative minima in near-surface CDOM abundance were also detected in the subtropical gyres. Therefore, a systematic study of these zones, with both their low [Chl] and low CDOM levels, can provide an answer to the initial question: from an optical viewpoint, do waters identical to, or approaching those encountered near Easter Island exist elsewhere in the world ocean? More generally, and from a biogeochemical viewpoint, the trophic status of these zones, their seasonality, their systematic difference or resemblance, and the interannual stability of their characteristics are also the topics of the present study.

A newly proposed technique allows the chromophoric organic material content to be quantified from remotely sensed data of ocean color (Morel and Gentili, 2009a). This technique will be applied in parallel with the [Chl] retrieval to carry out a comparative study of the various oligotrophic subtropical gyres. The location and extension of the selected zones inside each of the gyres (Table 1 and Fig. 1) were delimited in order to contain the most oligotrophic inner core. Note that these zones are far less extended than the ecological domains as defined in the sub-tropical regions by Longhurst (1995), or than the entire gyres as studied by McClain et al. (2004). 
Table 1. Geographical information for the six oligotrophic zones selected for the present study (see also map in Fig. 1); in addition, are included a mesotrophic site off Portugal, used for comparison (see text), as well as a sub-zone near Easter Island, denoted $E_{f}$, where an Argo float has been deployed during about 3 years.

\begin{tabular}{lcrrrrc}
\hline Location & Notation & \multicolumn{2}{c}{ Longitude } & \multicolumn{2}{c}{ Latitude } & Area $\left(10^{6} \mathrm{~km}^{2}\right)$ \\
\hline Easter Island zone & $\mathrm{E}$ & -125.0 & -100.0 & -30.0 & -20.0 & 2.794 \\
Mariana Islands zone & $\mathrm{M}$ & 150.0 & 165.0 & 10.0 & 20.0 & 1.787 \\
Brasilian Atlantic gyre & $\mathrm{B}$ & -32.0 & -25.0 & -22.5 & -12.5 & 0.823 \\
South-Sargasso Sea & $\mathrm{S}$ & -70.0 & -45.0 & 22.0 & 27.0 & 1.404 \\
South Indian gyre & $\mathrm{I}$ & 70.0 & 90.0 & -30.0 & -21.0 & 2.004 \\
Hawaii Islands zone & $\mathrm{H}$ & -170.0 & -150.0 & 10.0 & 18.0 & 1.916 \\
Atlantic off Portugal & $\mathrm{P}$ & -25.0 & -15.0 & 34.0 & 40.0 & 0.591 \\
Argo float (E) & $E_{f}$ & -115.0 & -101.0 & -29.0 & -24.0 & 0.773 \\
\hline
\end{tabular}

\section{Data and methods}

Satellite imagery (SeaWiFS) over the 1998-2007 period is considered for the present study. Yearly, monthly or eightday L3 composites $(9 \mathrm{Km})$ of the [Chl] distribution, the PAR(0) distribution (the daily Photosynthetically Available Radiation at the surface), and distribution of the CDOM index (chromophoric dissolved organic matter ) were used; they are the last products of the most recent NASA reprocessing (2009.1). The CDOM index is the factor defined and studied in Morel and Gentili (2009a), and denoted $\Phi$. The meaning of this $\Phi$ index can be summarized as follows. In case 1 waters, there exists a "mean" relationship between the CDOM content and the chlorophyll concentration [Chl] (Morel, 2009) of the form

$a_{\mathrm{y}}(\lambda)=\alpha(\lambda)[\mathrm{Chl}]^{0.63}$

where the CDOM content is expressed as an absorption coefficient (unit $\mathrm{m}^{-1}$ ) at a certain wavelength, $a_{\mathrm{y}}(\lambda)$. At the wavelength $\lambda=443 \mathrm{~nm}$ for instance, the $\alpha$ coefficient amounts to 0.0316. Natural variability around the mean $a_{\mathrm{y}} \leftrightarrow[\mathrm{Chl}]$ relationship is rather large; it is conveniently represented by introducing the index $\Phi$ (dimensionless) which modulates the mean relationship according to

$a_{\mathrm{y}}(443)=0.0316 \Phi[\mathrm{Chl}]^{0.63}$

The particular value $\Phi=1$ stands for the mean Case 1 waters conditions. If CDOM is in "excess" compared to its mean value as expected from the [Chl] value, then $\Phi$ is $>1 ; \Phi$ can as well be $<1$, when the CDOM content is below its expected average value.

The derivation of the $\Phi$ index from ocean color radiometric data is briefly recalled in what follows. It results from the simultaneous consideration of the spectral reflectance, $R(\lambda)$, at four wavelengths $(\lambda=412,443,490$ and $555 \mathrm{~nm})$, and then by forming the two independent ratios, $R(412) / R(443)$ and $R(490) / R(555)$, hereafter denoted $\boldsymbol{R}_{443}^{412}$ and $\boldsymbol{R}_{555}^{490}$. In mean case 1 waters, i.e., when $\Phi=1$, a univocal relationship links $\boldsymbol{R}_{443}^{412}$ to $\boldsymbol{R}_{555}^{490}$, and is represented by a unique curve within the $\boldsymbol{R}_{443}^{412}-\boldsymbol{R}_{555}^{490}$ plane. In this plane, a family of similar curves is produced when $\Phi$ is given various discrete values around 1 (Fig. 2, in Morel and Gentili, 2009a). For each pixel of the SeaWiFS imagery, $\Phi$ is simply obtained by considering the two ratios $\boldsymbol{R}_{443}^{412}$ and $\boldsymbol{R}_{555}^{490}$ computed from the reflectances retrieved at this pixel, and by comparing them with the curves drawn within the $\boldsymbol{R}_{443}^{412}-\boldsymbol{R}_{555}^{490}$ plane (see also discussion in Appendix A). In practice, an interpolation into a 2-D lookup table, which is numerically equivalent to the family of curves, allows the determination of the $\Phi$ index (available at ftp///oceane.obs-vlfr/pub/gentili/ CDM-index-Table.interpol). Once $\Phi$ has been determined, the coefficient $\mathrm{a}_{y}(443)$ can be computed through Eq. (1) by using the [Chl] value determined at the same pixel via the standard algorithm (actually the OC4 algorithm used in the last NASA reprocessing, labeled 2009.1). For the sake of concision, the quantity $a_{\mathrm{y}}(443)$ is also denoted $a_{\mathrm{y}}$, since there is no ambiguity about the wavelength.

As a consequence of the presence of yellow substance in varying proportions with respect to [Chl] (i.e., as a consequence of varying $\Phi$ values), the [Chl] values retrieved by using a standard univocal algorithm may be erroneous. Indeed, standard algorithms (as for instance OC4 presently used to retrieve [Chl]) implicitly suppose that the average proportions between CDOM and [Chl] are respected; in other words they imply that $\Phi \sim 1$. When $\Phi$ differs from unity, the [Chl] estimate is subsequently biased (Siegel et al., 2005; Hu et al., 2006; Morel and Gentili, 2009a, their Fig. 9). An overestimation occurs when $\Phi>1$, since the "excess" of CDOM is converted through the nominal algorithm into an increased [Chl] value; therefore the correction to be applied is a negative one. The converse holds true if $\Phi<1$. The corrected [Chl] values are conveniently obtained through the use of a lookup table with $\Phi$ and the initial (uncorrected) $\mathrm{Chl}$ value as entries, available at fttp///oceane.obs-vlfr/pub/ gentili/ChlCorrected-Table.interpol.

An additional remark is useful and deals with nomenclature and the meaning of the so-called quantities CDM and 

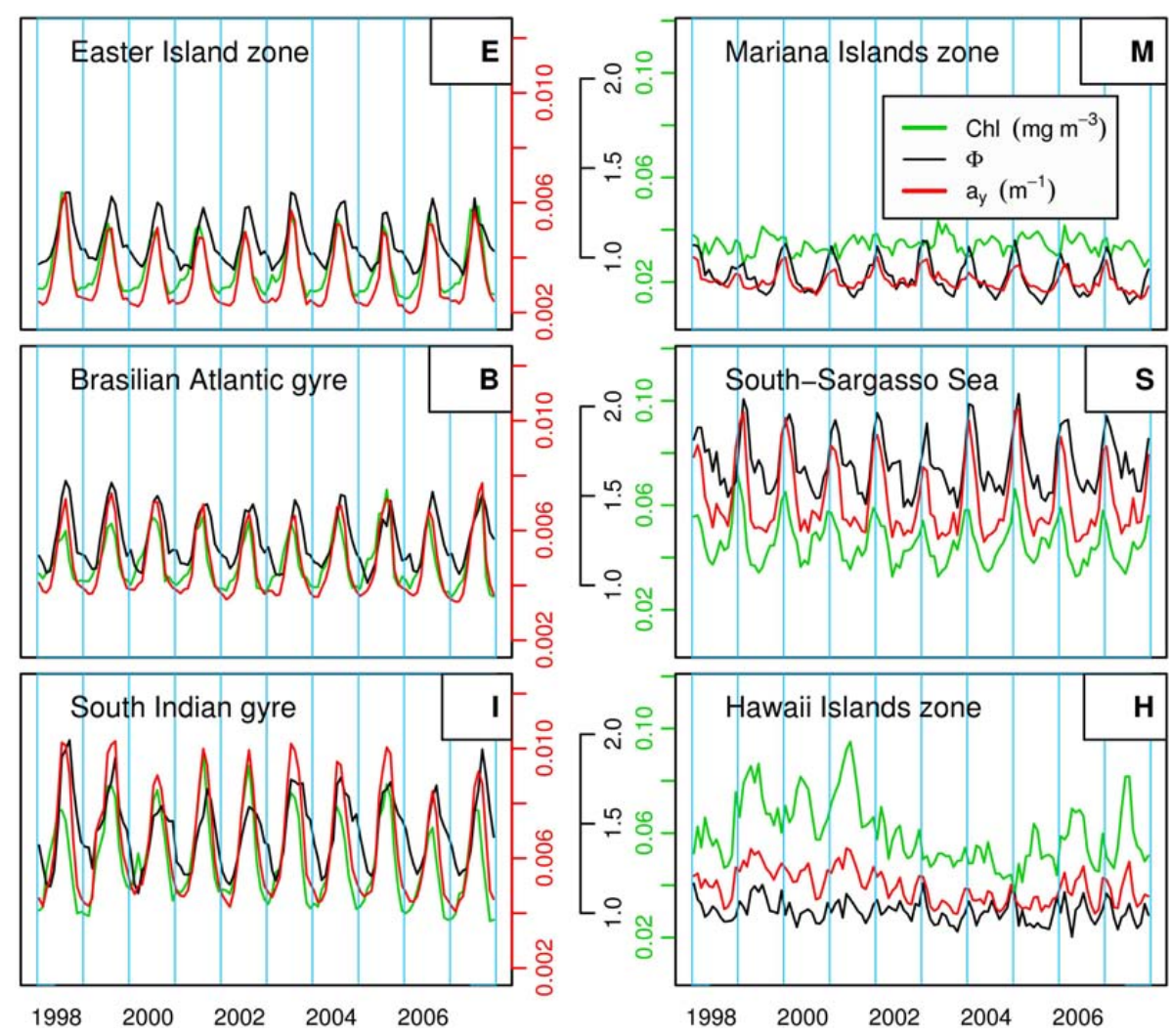

Fig. 2. Time series (1998-2007) of the three parameters, [Chl], $a_{\mathrm{y}}(443)$, and $\Phi$, as established from the monthly composites and by averaging the values of all pixels over each of the six selected zones (identifiers as in Table 1); to facilitate direct comparisons, the scales are identical for the six panels; green scale: $[\mathrm{Chl}]$ as $\mathrm{mg} \mathrm{m}^{-3}$; red scale $a_{\mathrm{y}}(443)$ as $\mathrm{m}^{-1}$; black scale, in the middle, $\Phi$, dimensionless.

CDOM. When developing the GSM method (Maritorena et al., 2002; Siegel et al., 2002), the CDM acronym, with the meaning of "colored detrital material", was introduced. It represents the combined absorption of colored detrital particles and of dissolved organic material. The latter component, which largely dominates the absorption process, is commonly referred to as CDOM (for Chromophoric dissolved organic matter, i.e., the matter able to pass through a membrane filter with $0.2 \mu \mathrm{m}$ pore size). The quantity which is retrieved here and used in the present study is close to CDOM (and is referred to as such), even if it does not exactly fulfill the definition (which involves filtration; see discussions in Morel and Gentili, 2009a; Bricaud et al., 2010).

\section{The selected geographic zones}

Six quadrangular domains within the five major anticyclonic gyre systems of the three oceans (McClain et al., 2004) were considered. These zones (except the Hawaiian zone - see comments below) were selected to coincide with the most oligotrophic cores of each gyres in the Northern and Southern Hemispheres (Fig. 1 and Table 1 provide their locations and limits). The central parts of the gyres were delimited somewhat arbitrarily by considering the monthly [Chl] composites encompassing firstly the whole gyre systems, and then by progressively reducing (down to $\sim 1-3 \times 10^{6} \mathrm{~km}^{2}$ ) the area under consideration, in order to isolate the "cores" of each system. The core is assumed to be typified by minimal [Chl] concentrations, compared to the values of the entire gyre in the same month, and, if possible, it must be spatially sufficiently homogeneous. Simple statistical tools guide this process, by examining the evolution of the [Chl] means and standard deviations while progressively shrinking the boundaries of the quadrangular zones. The standard deviations (sd), describe the inter-pixel variability, and the coefficients of variation, $\mathrm{cv}(\mathrm{cv}=\mathrm{sd} / \mathrm{mean}$, in \%) thus provide a quantification of the spatial heterogeneity within each zone and for a given month. These coefficients are generally comprised for the six zones between 20 and $40 \%$ in terms of [Chl]; exceptionally, higher values $(\sim 60 \%)$ are observed during the blooming period (see below); in terms of $a_{\mathrm{y}}$, the spatial distribution is more homogeneous, with $\mathrm{cv}$ between 10 and $20 \%$. This method is similar to that described in Fougnie et al. (2002).

In such central positions within the anticyclonic circulations, the lateral advective exchanges are supposedly reduced to their minimum in the selected zones. The low [Chl] values 
do not imply a constancy in the concentration. Actually, a seasonal [Chl] signal clearly occurs in four of the six selected zones (as discussed later on), while in the two others (both in the North Pacific), this signal fluctuates rather irregularly and is spatially less homogeneous.

At first sight (Fig. 1), the CDOM distribution in the upper layer bears a rough resemblance to the phytoplanktonic chlorophyll distribution. The modulation introduced by the variation of the $\Phi$ factor (Eq. 1) impedes a tight correlation between the two quantities. Anyhow, the oligotrophic areas selected on the basis of their low [Chl] content, appear also to be characterized by low $a_{\mathrm{y}}$ values.

The South Pacific gyre is the largest subtropical anticyclonic gyre of the world ocean; its hyperoligotrophic character was already acknowledged (Claustre et al., 2008; Morel et al., 2007a). Its central zone, around Easter Island, is presently selected. Its counterpart in the Northern Hemisphere is a huge anticyclonic system, extending from Hawaiian Islands to Mariana Islands. The examination of ocean color imagery showed that the really oligotrophic waters are lying in the westernmost part of the gyre, i.e., east of Mariana Islands; this zone, actually within the so-called warm pool, was thus selected.

In the Atlantic ocean, the generally low level of phytoplankton in the Sargasso Sea has been known for a long time (Menzel and Ryther, 1960, 1961), and regularly documented (Bermuda Atlantic Time-Series Study or "BATS" program; see e.g., Michael and Knap, 1996). The area presently selected in the southern Sargasso Sea, between $22^{\circ}$ and $27^{\circ} \mathrm{N}$, lies south of the BATS deployment area $\left(\sim 31^{\circ} 40 \mathrm{~N}\right)$, where the [Chl] level may be moderately high in winter (Garver and Siegel, 1997). The selected area is thus close to the site studied by $\mathrm{Hu}$ et al. (2006) and presumably more stable. Indeed, the mesoscale eddy activity, which may include intermittent drift of cold core rings at the latitude of Bermuda, is weakening southward, at the selected $\left(<27^{\circ} \mathrm{N}\right)$ latitudes (Steinberg et al., 2001).

The South Atlantic gyre off Brazil is similarly characterized by a low algal content with apparently a limited E-W extension probably due to the remote influence of the eutrophic Benguela system (Fig. 1). Data obtained along the Atlantic Meridional Transect (Aiken et al., 2009) have regularly confirmed the low [Chl] values in this area. Midway between Madagascar and Australia, in the South Indian ocean, the scarcely documented anticyclonic gyre is systematically seen by ocean color sensor as an oligotrophic zone, and thus was retained for the present study.

Finally, another area situated south of the Hawaiian Islands has also been considered. Actually, this area which belongs also to the North Pacific subtropical gyre system, is no longer located in its center, but at its eastern periphery. It does not exhibit the lowest [Chl] level in the North Pacific, which, as said before, are found westward, near the Mariana islands, in the quieter center of the gyre. This area was nevertheless considered for a possible comparative study, in particular because in situ data are regularly gathered at the ALOHA reference station, and at the MOBY instrumented site, devoted to satellite calibration and validation activities and optical measurements. The region finally kept, however, is more in the south (between 18 and $10^{\circ} \mathrm{N}$ ), about $500-1300 \mathrm{~km}$ south of the Hawaiian archipelago. If it is outside of the eddy activity field in the lee of the islands (Calil and Richards, 2010), it lies yet inside the eastern branch of the North Equatorial current, driven westward by the trade winds (Wyrtki and Kilonsky, 1984). Lateral advection and occurrence of eddy-related random fluctuations cannot be excluded in this zone.

\section{Results}

The monthly [Chl] and $\Phi$ SeaWiFS values have been spatially averaged over each of the six zones. With these values, the corresponding CDOM absorption values, $a_{\mathrm{y}}(443)$, have been straightforwardly derived via Eq. (1). These monthly quantities are displayed in Fig. 2 from January 1998 to December 2007. Then, mean annual cycles (Fig. 3) were produced for each zone by cumulating and averaging the cycles observed during the ten years (those in Fig. 2); the standard deviation which is computed and displayed as vertical bars characterizes, for each month, the year-to-year variability of the quantity involved, [Chl], $a_{\mathrm{y}}$, and $\Phi$. Finally, a general annual mean value for each zone, and the pooled standard deviations (the average of the monthly standard deviations) were also produced from the cycles shown in Fig. 3; the results are given in Table 2, where the 6 zones have been ranked according to increasing [Chl] values.

When needed, the eight-day [Chl], $\Phi$, and PAR composites have also been examined ("PAR" means "photosynthetically available radiation", from 400 to $700 \mathrm{~nm}$ ).

\subsection{The chlorophyll concentration}

The permanent oligotrophic character is confirmed within the six selected areas. Indeed, the annual mean [Chl] values (Table 2), which are below $0.05 \mathrm{mg} \mathrm{m}^{-3}$ in all zones except near Hawaii $\left(0.06 \mathrm{mg} \mathrm{m}^{-3}\right)$, are low compared with the mean value for the deep global ocean amounting to $0.193 \mathrm{mg} \mathrm{m}^{-3}$ (Wang et al., 2005).

The South Pacific gyre (Easter Island, E) definitely appears to be hyperoligotrophic (mean [Chl] $0.026 \mathrm{mg} \mathrm{m}^{-3}$ ). The western part of North Pacific gyre (near Mariana Islands, M) is similarly and steadily hyperoligotrophic. In contrast, the highest mean [Chl] value is observed near Hawaii $(\mathrm{H})$, at the eastern periphery of the gyre. The South Atlantic (B) and Indian (I) gyres, as well as the Sargasso Sea (S) are in intermediate position, with annual mean [Chl] values ranging from 0.038 to $0.049 \mathrm{mg} \mathrm{m}^{-3}$. Compared to the seasonal [Chl] values in the BATS and HOT sites (Figs. 1 and 2 in Werdell et al., 2007), the present values in $\mathrm{H}$ and $\mathrm{S}$ are notably lower, 
Table 2. Annual mean values over the ten years (1998-2007) period of the quantities [Chl] $\left(\mathrm{mg} \mathrm{m}^{-3}\right), \Phi$ (dimensionless), and $a_{\mathrm{y}}(443)$ $\left(\mathrm{m}^{-1}\right)$, for each zone, including "P" (Portugal) and " $E_{f}$ " (the sub-zone in the E zone). The (12) average monthly values of the same quantities for each zone, as displayed on Fig. 3, are used to obtain the annual mean values. The pooled standard deviations are simply the average of the standard deviations pertinent to each month (those shown in Fig. 3).

\begin{tabular}{ccccccccc}
\hline & \multicolumn{2}{c}{ Chl } & \multicolumn{2}{c}{ corr. Chl } & \multicolumn{2}{c}{$\Phi$} & \multicolumn{2}{c}{$a_{\mathrm{y}}$} \\
& mean & st.dev. & mean & st.dev. & mean & st.dev. & mean & st.dev. \\
\hline $\mathrm{E}$ & 0.026 & 0.003 & 0.026 & 0.003 & 1.085 & 0.041 & 0.0033 & 0.0003 \\
$\mathrm{M}$ & 0.034 & 0.003 & 0.037 & 0.003 & 0.891 & 0.038 & 0.0031 & 0.0002 \\
$\mathrm{~B}$ & 0.038 & 0.004 & 0.036 & 0.004 & 1.256 & 0.043 & 0.0048 & 0.0003 \\
$\mathrm{~S}$ & 0.046 & 0.004 & 0.038 & 0.003 & 1.681 & 0.064 & 0.0071 & 0.0005 \\
$\mathrm{I}$ & 0.049 & 0.006 & 0.043 & 0.006 & 1.457 & 0.085 & 0.0065 & 0.0006 \\
$\mathrm{H}$ & 0.060 & 0.012 & 0.061 & 0.012 & 1.009 & 0.053 & 0.0050 & 0.0006 \\
$\mathrm{P}$ & 0.169 & 0.037 & 0.124 & 0.033 & 2.153 & 0.304 & 0.0204 & 0.0041 \\
$E_{f}$ & 0.024 & 0.006 & 0.028 & 0.006 & 1.077 & 0.086 & 0.0032 & 0.0006 \\
\hline
\end{tabular}

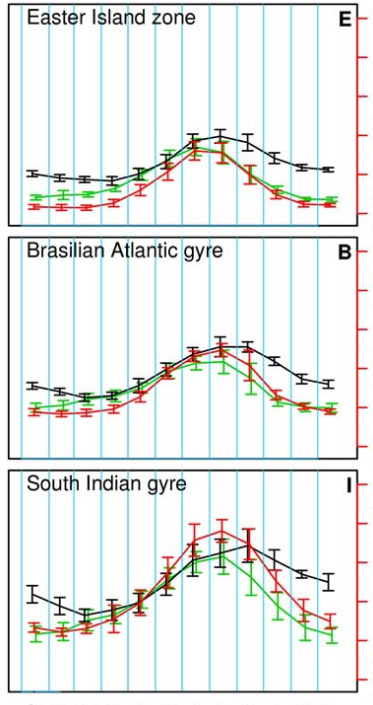

Ja F M A M J J A
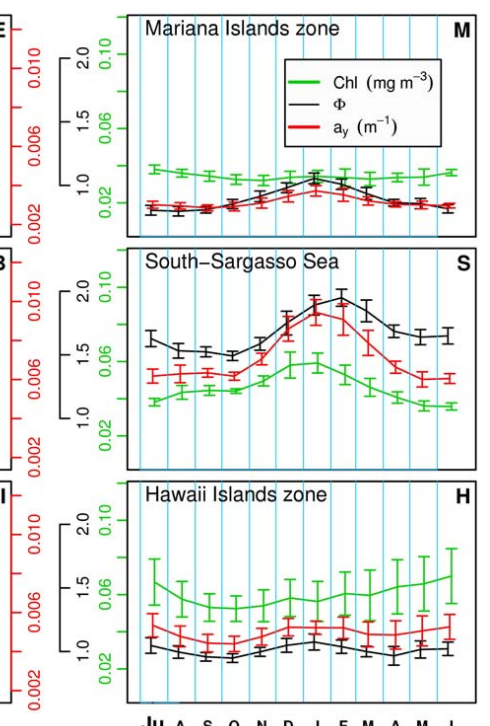

Fig. 3. Climatological annual cycles (temporal resolution: one month) of the three parameters, [Chl], $\Phi$, and $a_{\mathrm{y}}(443)$ within each zone; the cycles are obtained by averaging over 10 years the time series displayed in Fig. 2. Same symbols, colors, units, and scales as in Fig. 2. The vertical bars correspond to \pm 1 standard deviation computed for each month over the $10 \mathrm{y}$ period, and express the yearto-year variability of the monthly mean values inside each zone.

as expected from their location southwardly shifted with respect to the BATS and HOT sites.

The [Chl] time series for each zone can be seen in Fig. 2 over the $10 \mathrm{y}$ period, and the mean annual cycles in Fig. 3. The interannual variability is reflected by the pooled standard deviation around the mean annual value (the $\sigma$ values in Table 2). The corresponding coefficients of variation ( $\sigma /$ mean) amount to about $10 \%$ everywhere, apart from the Hawaiian region where it reaches $20 \%$. In the E, B, I, and
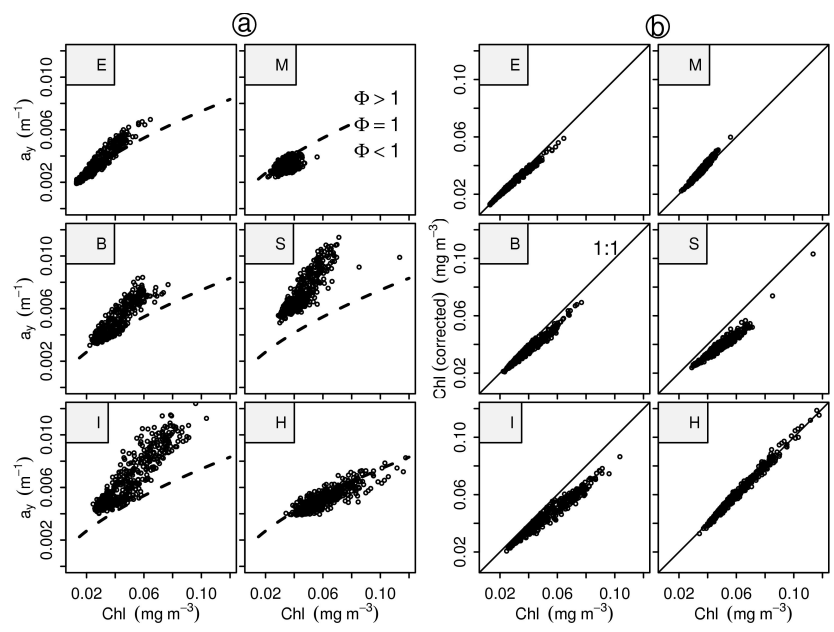

Fig. 4. For the left hand column (sites in the Southern Hemisphere) the year starts with January (Ja); for the right hand column (Northern Hemisphere) the year starts with July ( $\mathrm{Ju})$; by this way, the winter solstice is in the middle of the figures, whatever the hemisphere. (a) Spatially averaged quantities [Chl] (via OC4 algorithm), and $a_{\mathrm{y}}(443)$ (via Eq. 1) from eight-day composites for each zone; the dashed curve represents the relationship when $\Phi=1$; above and below this curve are the domains where $\Phi$ is $>1$ or $<1$, respectively. (b) Corrected [Chl] versus nominal [Chl] for each zone; the black line is the $1: 1$ line.

S zones seasonal [Chl] cycles occur (Fig. 2) and are regular repeated from year to year. In contrast, the seasonal [Chl] signals are rather irregular in the North Pacific gyre (M and $\mathrm{H})$. While in $\mathrm{M}$ the [Chl] signal is very weak and its mean level low (Fig. 2), in H, [Chl] values may intermittently exceed $0.08 \mathrm{mg} \mathrm{m}^{-3}$, and inter-annual disparities are obvious (see also Fig. 4). 


\subsection{The CDOM content}

The CDOM absorption coefficient in surface waters exhibits in the six zones low annual mean values. They agree with field values in the South Pacific gyre (Bricaud et al., 2010), and qualitatively, with those measured at $325 \mathrm{~nm}$ by Nelson et al. (2010). The present $a_{\mathrm{y}}(443)$ values range from about 0.0031 to $\sim 0.0071 \mathrm{~m}^{-1}$ (Table 2); these low values are to be compared with the median value for the whole ocean amounting to $\sim 0.009 \mathrm{~m}^{-1}$ (Morel and Gentili, 2009a). From this point of view, the selection of the oceanic zones, which has been made on the basis of [Chl], would have remained almost unchanged if, instead, a criterion based on CDOM absorption was used (compare upper and lower panels in Fig. 1). The ordering of the zones would have been different, however. Indeed, the $\Phi$ values are either below or above 1 , so that the relative $[\mathrm{Chl}]-a_{\mathrm{y}}$ proportions vary from one area to another one. With the highest average $\Phi$ value $(\sim 1.68 \pm 0.30)$ in the Sargasso Sea, there is a permanent CDOM "excess", and the mean $a_{\mathrm{y}}(443)$ value amounts to $\sim 0.0071 \mathrm{~m}^{-1}$, versus $0.0045 \mathrm{~m}^{-1}$, the value to be expected if $\Phi$ was unity for a [Chl] value equal to $0.046 \mathrm{mg} \mathrm{m}^{-3}$.

Conversely, $\Phi$ is notably $<1$ near the Mariana Islands, which denotes a CDOM content steadily below the average; the mean $a_{\mathrm{y}}(443)$ value found in this zone $\left(0.0031 \mathrm{~m}^{-1}\right) \mathrm{ac}-$ tually is the lowest one, even slightly below the value near Easter Island. The region south of Hawaii also exhibits rather low $a_{\mathrm{y}}(443)$ values. In the Northern Hemisphere, the difference between the Pacific and Atlantic oceans is striking, as also shown by Fig. 3. The interannual coefficients of variation for $a_{\mathrm{y}}(443)(\sigma / \mathrm{mean}$, taken in Table 2$)$ are, as for [Chl], about $10 \%$ or slightly less.

The diversity of the various oligotrophic domains with respect to their respective [Chl] and CDOM contents is also indirectly illustrated by Fig. 4a, where the eight-day mean [Chl] and contemporaneous $a_{\mathrm{y}}(443)$ values are displayed. The relative proportions CDOM-to-[Chl], (i.e., the $\Phi$ index) appear to be a typical trait of each region.

\subsection{The $\Phi$ index and corrected [Chl] values}

In the three Pacific zones (E, M, H), the $\Phi$ index is close to, or even below unity, while it is above 1 in the Atlantic and Indian gyres (Fig. 4a). It also exhibits a seasonal pattern (except near Hawaii) to be discussed later. The amplitude of the variations in $\Phi$ is less than it is for the other quantities, which means that $\mathrm{CDOM}$ and $[\mathrm{Chl}]$ remain partly correlated in their variations. The interannual coefficient of variation (cv) for $\Phi$ amounts to about $4-5 \%$, i.e., half those for CDOM and [Chl. If, as noted above, the CDOM-to-[Chl] proportions are rather site specific, they nevertheless exhibit periodic variations (shown in Figs. 2 and 3).

As in the present study $\Phi$ is never far from 1, the corrections (in both directions) to be applied to the initial [Chl] values remain small (Table 2), except in the Sargasso Sea

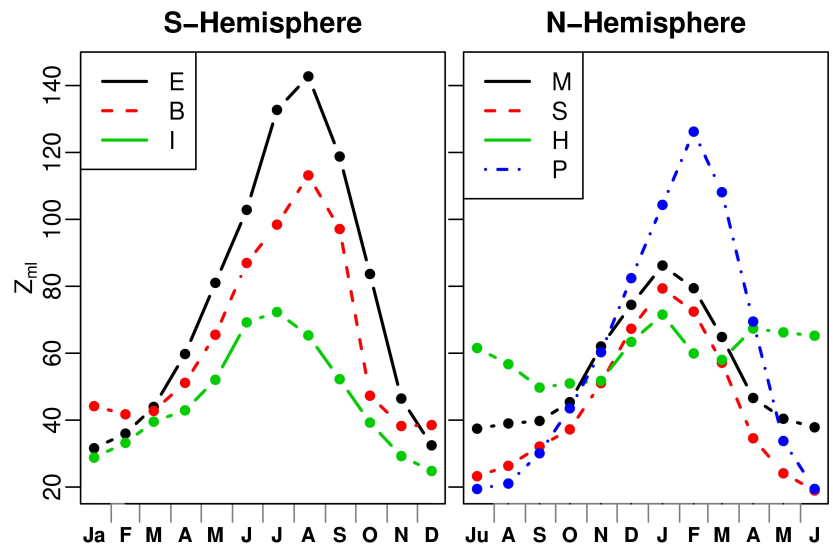

Fig. 5. Monthly values of the depth $(\mathrm{m})$ of the mixed layer $\left(Z_{\mathrm{ml}}\right)$ extracted from the climatology published by de Boyer Montegut et al. (2004), when the variable density criterion is used (the DReqDT0.2 product) and when the reference depth is set at $10 \mathrm{~m}$; the $Z_{\mathrm{ml}}$ values which are displayed are obtained by averaging the $Z_{\mathrm{ml}}$ data ( $2^{\circ}$ by $2^{\circ}$ grid) over each box shown in Fig. 1 . As in Fig. 3, the month scale begins with January, for the Southern Hemisphere (left panel); and in July for the Northern Hemisphere (right panel). Note that the site "P" (off Portugal) is not within an oligotrophic regime (see text).

and Indian Ocean, where the subtractive corrections amount to $\sim 15-20 \%$. In North Pacific ( $\mathrm{M}$ and $\mathrm{H}$ ), there is practically no correction, as it can be seen on Fig. $4 \mathrm{~b}$ (derived from Fig. 4a) where the corrected [Chl] values are plotted versus the (OC4) initial [Chl] values.

\subsection{Similarities and differences between the oligotrophic gyres}

The [Chl] and $a_{\mathrm{y}}(443)$ seasonal variations within the six zones over the 1998-2007 decade (Figs. 2 and 3) present two kinds of patterns, which can be distinguished as follows:

1. A first group includes four zones, namely the S-Pacific, S-Atlantic, S-Indian gyres, and the southern sector of the Sargasso Sea (E, B, I, S). In these zones the seasonal cycles are strongly printed, with roughly coincident maxima in both [Chl] and $a_{\mathrm{y}}$. A factor of $\sim 2$ characterizes the amplitude (maximum-to-minimum) of these seasonal cycles, for [Chl] as well as for CDOM. These maxima occur within the two months following the winter solstice of the corresponding hemisphere; they approximately coincide with the maximal extent of the mixed layer (Fig. 5, where the monthly average mixed layer, $Z_{\mathrm{ml}}$, are displayed for the six zones). The [Chl] and CDOM seasonal signals, of sinusoidal and symmetrical appearance, are very similar in the three locations of the Southern Hemisphere, with a wider amplitude in the Indian Ocean. Although regular, the seasonal patterns in the Sargasso Sea appear more complicated, in 
particular because a secondary maximum occurs at the end of September and concerns both [Chl] and $a_{\mathrm{y}}$. The seasonal cycles of the $\Phi$ index are also regular; despite the rather parallel evolutions of $a_{\mathrm{y}}$ and [Chl], their relative proportions are not constant, but seasonally slightly changing. As a general rule, the $\Phi$ maximum is shifted (about one month) with respect to the $a_{\mathrm{y}}$ maximum; a similar shift also affects the minima.

2. The second group includes the two locations in the North Pacific ( $\mathrm{M}$ and $\mathrm{H}$ ), where the variations in [Chl] and $a_{\mathrm{y}}$ appear less regular, partly correlated in $\mathrm{H}$ and rather uncorrelated in $\mathrm{M}$; in both sites, the $\Phi$ and $a_{\mathrm{y}}$ cycles remain concomitant, however. Actually, there are important differences between $\mathrm{M}$ and $\mathrm{H}$. Whereas the average [Chl] value in $\mathrm{H}$ is the highest found in oligotrophic areas (Table 2), the [Chl] value in $\mathrm{M}$ is among the lowest ones; the spatial heterogeneity in terms of [Chl] remains high (cv 50\%) in all seasons, and low $(\sim 20 \%)$ for $a_{\mathrm{y}}$. In M, a situation reversed with respect to those encountered in the first group prevails. Indeed, instead of a coincident phasing, there is a half year shift between the (weak) maximum in [Chl] in July, and the distinct maximum in $a_{\mathrm{y}}$ occurring in January. South of Hawaii, the strong and concomitant $[\mathrm{Chl}]$ and $a_{\mathrm{y}}$ fluctuations (Fig. 2) appear somewhat erratic; in absence of significant pycnocline motion (Fig. 5), they probably are the consequence of lateral advective intrusions and mesoscale eddy activity. In support to this second hypothesis, it can be noted that [Chl] and $a_{\mathrm{y}}$ fluctuate globally in phase, while the $\Phi$ index remains close to 1. The mean annual cycles (Fig. 3) tend to reveal in $\mathrm{H}$ and $\mathrm{M}$ a weak [Chl] maximum in summer (June-July), with a particularly low maximum-to-minimum [Chl] ratio $(\sim 1.2)$; the CDOM maxima are in January (and perhaps another $a_{\mathrm{y}}$ maximum occurs in July, south of Hawaii).

It is worth noting that the presence (Sargasso Sea) and the quasi-absence (Hawaii) of seasonality in $a_{\mathrm{y}}$ were already pointed out by Siegel et al. (2002), who produced and studied time series of CDM in the BATS and HOT sites. Their CDM values are slightly above the present $a_{\mathrm{y}}$ values. Actually the algorithms providing CDM and $a_{\mathrm{y}}$ differ, possibly leading to a small divergence (with $\mathrm{CDM}>a_{\mathrm{y}}$ ) as already noticed (Fig. 7 in Morel and Gentili, 2009a). Besides, the selected S and $\mathrm{H}$ zones were both southwardly shifted compared to the BATS and HOT sites, with, as discussed above, the intent of isolating the most oligotrophic cores.

\section{Analysis of the seasonal variations}

According to the subtropical latitude of the zones under study, the winter vertical mixing, that generally occurs shortly after the winter solstice (Fig. 5), is much less intense

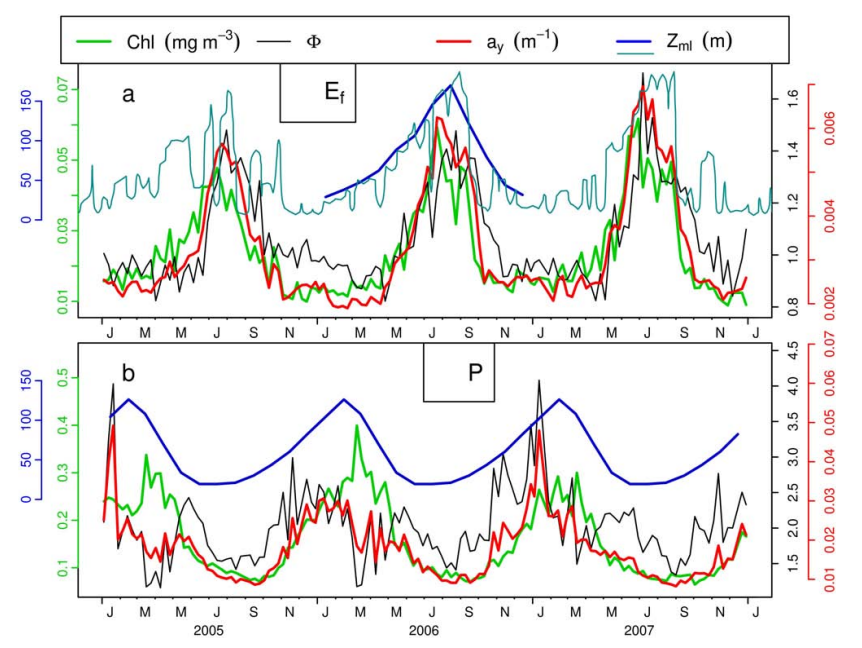

Fig. 6. (a) The three parameters, [Chl], $a_{\mathrm{y}}(443)$, and $\Phi$, are plotted with the same symbols and scales as in Fig.2, but they are computed from the 8-day SeaWiFS L3 composites, and for a sub-zone $\left(109^{\circ}-115^{\circ} \mathrm{W}, 24^{\circ}-29^{\circ} \mathrm{S}\right)$ inside the E zone, where an ARGO float (WMO \# 3000302) was deployed and has provided data at the 10day frequency during the years 2005-2007. The depth $(\mathrm{m})$ of the mixed layer $\left(Z_{\mathrm{ml}}\right)$ was computed from the T-S data recorded by this float, and by using a density criterion $(\Delta \sigma=0.03)$; the corresponding results are shown as the (thin) blue curve. The thick blue curve represents the $Z_{\mathrm{ml}}$ values computed for the same zone from the climatology (de Boyer Montegut et al., 2004). (b) for the same years, [Chl], $\mathrm{a}_{y}(443)$, and $\Phi$ are plotted also at 8-day resolution, for the zone "P" (off Portugal, see Tables 1 and 2). Note the change of scales between panel (a) and panel (b) (see also values in Table 2). The blue (thick) curve represents the climatological $Z_{\mathrm{ml}}$ values for the "P" zone (from data in de Boyer Montegut et al., 2004).

than in temperate mid-latitudes. Despite its limited amplitude, the deepening of the pycnocline is apparently sufficient to allow some underlying waters, with their nutrients and unbleached yellow substance content, to shoal and to be exposed to solar radiation. The response in terms of chlorophyll concentration (perhaps influenced by photo-adaptation in wintertime - see discussion below) is fast, so that the [Chl] and CDOM peaks associated with vertical mixing events are simultaneous. This simultaneity, even at high frequency, is supported by the detailed examination of the SeaWiFS data obtained at the eight-day resolution near Easter Island (Fig. 6a); the mixed layer depth, as derived from the data recorded in this zone by an Argo float at a ten-day resolution (see legend), is also displayed on this figure.

The $\mathrm{E}$ zone represents the typical scenario among the zones within group 1 , which regularly exhibit a winter [Chl] maximum, thus a pelagic seasonality consistent with Longhurst's (1995) Model 3. The progressive development of the bloom begins in fall; it culminates in July-August in the Southern Hemisphere and in January in the Sargasso Sea; then [Chl] declines smoothly. Compared to stronger mid-latitude "spring blooms", the subtropical winter bloom 


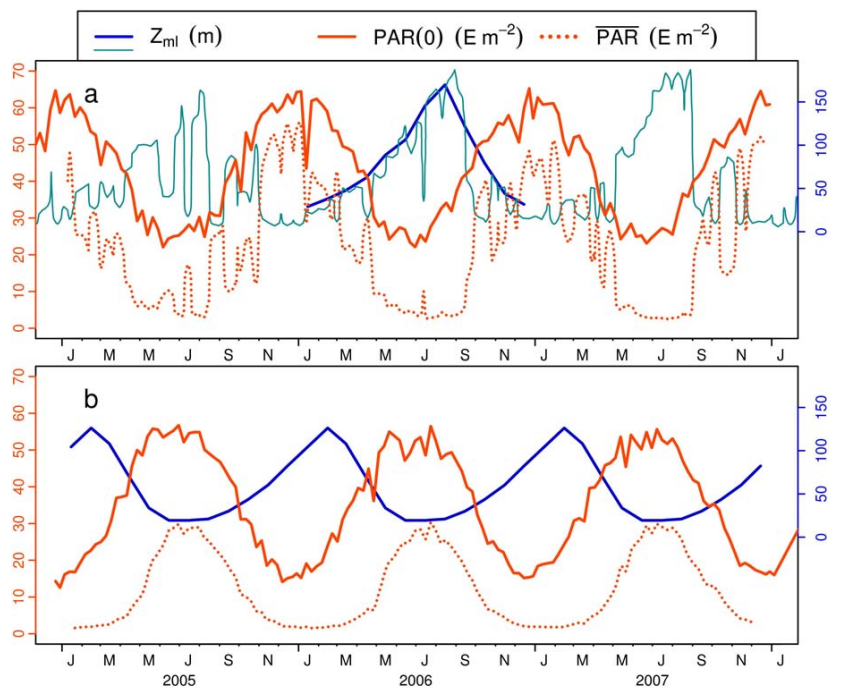

Fig. 7. The panels (a) and (b) are for the same zones as represented in Fig. 6a and b, and the depths of the mixed layer are reproduced from these panels. In addition are displayed the surface daily PAR( 0 ) values provided by NASA and averaged over the zones in question (the solid lines), and $\overline{\mathrm{PAR}}$, the mean values computed for the mixed layer (the doted lines; see Appendix B). Note that the scales are the same in both panels.

appears modest, as the ratio between the [Chl] maximum and its minimum barely reaches 2.5 . The temporal evolution of the CDOM content mimics that of [Chl] with coinciding peaks and a maximum-to-minimum ratio also of about 2. The $a_{\mathrm{y}}-[\mathrm{Chl}]$ proportions are periodically changing, as demonstrated by the $\Phi$ cycles which generally experience their maximum about one month ( 8 to 40 days) after the [Chl] peak. This time lag could mean that the decrease in CDOM, presumably due to the photo-bleaching process, is slower than the [Chl] decline. It may also indicate that a certain amount of CDOM is locally produced by algae during their degradation. This phase lag persists during the whole summer, since $\Phi$ does not reach its minimum before October (N-Hemishere) or April (S-Hemisphere), i.e., when [Chl] has already begun to increase again. Similar observations of time lags were made by $\mathrm{Hu}$ et al. (2006) in a location within the Sargasso Sea $\left(65^{\circ} \mathrm{W}-27.5^{\circ} \mathrm{N}\right)$. In passing, it is worth noting that their ag-443 values (Hu et al's notation), within the range $0.0035-0.009 \mathrm{~m}^{-1}$, and the present $a_{\mathrm{y}}(443)$ values are in excellent agreement as regards their magnitude and seasonality.

There is also another systematic and rather enigmatic feature appearing in the $\Phi$ cycles (Fig. 2): it consists of a "shoulder" occurring when [Chl] approaches its minimum around January (E, B, and I), or in June-July within the Sargasso Sea; in this Sea, this feature is particularly well developed. Its origin remains unclear.

For the second group ( $\mathrm{M}$ and $\mathrm{H})$, the situation and temporal evolution markedly differ from those observed within the first group, and the regularity of the seasonal cycling (for
[Chl] and CDOM) is to a large extent broken. In these zones, the supply of nutrients and unbleached CDOM to the upper layer seems to be hampered, with the consequence that the seasonality in the signals is smoothed out. In $\mathrm{H}, Z_{\mathrm{ml}}$ is almost constant during the year (around $60 \mathrm{~m}$, see Fig. 5); vertical mixing events are thus limited or inexistent; the episodic strong [Chl] peaks, occurring in mid-summer, are not related to such improbable events and have another cause (see below). In $\mathrm{M}$, from about $40 \mathrm{~m}$ in summer, the MLD reaches $80 \mathrm{~m}$ in January, as in the Sargasso Sea where a strong seasonality in optical properties is observed; in contrast, such a seasonality is not observed in the Mariana zone. Maybe, in this zone, the maximal MLD is insufficient to reach the nutricline, or the nutrient reservoir is partly depleted (e.g., Palter et al., 2005). Also, due to heavy rainfall in this zone, the existence of strong haloclines could impede active convection, in such a way that the near-surface salinity-stratified layers are insulated from the thermocline itself by the presence of relatively thick barrier layers (Maes et al., 2006; Sato et al., 2004).

As for CDOM, the common trait of the $\mathrm{M}$ and $\mathrm{H}$ zones is a rather flat annual mean (Fig. 3). In M, both $a_{\mathrm{y}}$ and $\Phi$ are low all the year round within the less saline well-lit surface waters of the warm pool. A seasonal CDOM cycling, however, is clearly detected in $\mathrm{M}$ along the 10 years record (Fig. 2), with a weak maximum observed in winter (January), and a systematic minimum in summer (April to September) when the solar bleaching is particularly effective. It is worth noting that, for unclear reason, the weak $a_{\mathrm{y}}$ and [Chl] maxima are in opposite phase (Figs. 2 and 3). On the contrary, south of Hawaii, the main CDOM maxima, in June-July, coincide with the [Chl] pulses. More generally, the rather erratic $a_{\mathrm{y}}$ fluctuations in $\mathrm{H}$ (Fig. 2) roughly parallel those of [Chl], suggesting that the common cause would be some lateral advective processes inside the turbulent eastern branch of the North Equatorial current (Wyrtki and Kilonsky, 1984).

\section{Discussion and conclusion}

With significantly differing [Chl] and CDOM content, the six zones are not identical from an optical viewpoint.

The South Pacific gyre, the world's largest oceanic desert, is the area where the clearest waters were found so far (Morel et al., 2007a). The area near Mariana islands, with a slightly higher mean [Chl] content and a similar low CDOM content (see also fluorescence measurements in Omori et al., 2010), is probably of exceptional clarity regardless of the season. According to the present results, no other oligotrophic gyres, beside these Pacific systems, exhibit such low pigment and yellow substance contents. In particular, the Sargasso Sea which is often considered as an archetype for oligotrophic regimes, is certainly not the bluest sea. Even if the lowest CDOM values in the North Atlantic were observed in this zone (Nelson et al., 2007), they still are the highest ones 
among the six zones presently considered. Note that a similar statement was already formulated for the Mediterranean Sea despite its renowned oligotrophy; in effect, the Mediterranean waters are not as blue as it could be expected from their low [Chl] level, essentially because of a relative CDOM excess (Morel and Gentili, 2009b).

For in-flight calibration or inter-comparison of ocean color space sensors over known targets, the seasonal variations here described have to be accounted for, as they modulate the water reflectance in the blue and UV spectral domains. The seasonality is rather reproducible from year to year in four sites (E, B, I, and S) and thus predictable for calibration purposes. The site near Mariana Islands, deprived of seasonal signals, is very stable and would be especially convenient for ocean color calibration (when cloud free).

Recent studies (see e.g. Behrenfeld et al., 2006; Martinez et al., 2009; Boyce et al., 2010), showed that long-term trends or decadal oscillations can be detected in oceanic phytoplankton biomass. According to Polovina et al. (2008; see also Irwin and Oliver, 2009), the ocean's most oligotrophic waters would be expanding. As a possible consequence, the centers of the main oligotrophic gyres are perhaps becoming even more oligotrophic. Yet, the attempt to detect such a temporal evolution over the 10-year time series has not revealed any significant trend inside the oligotrophic cores themselves.

From a biochemical viewpoint, the oligotrophic regimes in the subtropical gyres are akin without being identical; in particular, the two groups defined above exhibit distinctive features. In the two North Pacific sites, the seasonal signals for both [Chl] and $a_{\mathrm{y}}$ are either erratic (in $\mathrm{H}$ ) or featureless (in $\mathrm{M}$ ), and there is no clear explanation to such behaviors, probably related to the permanence of a rather thin mixed layer and the absence of deep convection. In contrast, within the four sites of the first group (i.e., E, B, I, and S), repetitive seasonal signatures appear, and the concomitance of the [Chl] and CDOM annual cycling, in phase and relative amplitudes, is striking. This feature calls for a comment, and an attempt to find an explanation. Several scenarios are possible and three will be examined. They involve as main processes the local production of CDOM by algae, the algal photoacclimation (at low light) on a par with the reduction of the bleaching during winter, and finally, the vertical flux of nutrients and CDOM associated with the winter convection.

To explain the simultaneous rise in $[\mathrm{Chl}]$ and $\mathrm{CDOM}$, it is tempting to imagine that the dissolved colored matter is straightforwardly produced by the algal population, either directly (cell lysis, excretion), or indirectly (through prompt "sloppy" feeding and heterotrophic activity). The CDOM content would thus go along with the phytoplankton growth. Such an explanation implies that the production of CDOM by algae is an extremely fast process. Actually, this hypothesis was adopted by Hu et al. (2006). These authors also based their interpretation on the small time lag (by about two weeks) they have observed between the $[\mathrm{Chl}]$ maximum and the development of a CDOM maximum. The results obtained here, even at the eight-day resolution, do not show that such a lag is systematic nor is a significant feature; at this resolution, the highest $a_{\mathrm{y}}$ values remain closely associated with the highest [Chl] values (Fig. 2; see also Fig. 6a). Actually, the coincidence between the (Chl) and the $a_{\mathrm{y}}$ peaks, which seems to be shared by the subtropical areas, is not, by far, a general rule; a previous result, summarized as follows, has to be considered. In temperate latitude, namely in the Western Mediterranean Sea, as well as in the entire zonal $30^{\circ}-$ $45^{\circ} \mathrm{N}$ belt, (Morel and Gentili, 2009b), it has been observed that the onset of the CDOM increase occurs when the autumnal process of the thermocline erosion begins, so that the CDOM maximum (in January), precedes the vernal bloom (in March). For a detailed confirmation of this process, an area was selected in the transition zone at latitudes between $34^{\circ}$ and $40^{\circ} \mathrm{N}$, off Gibraltar and outside of the Portuguese upwelling (Fig. 1, Table 1). The corresponding time series at eight-day resolution, displayed in Fig. 6b, clearly shows that the maximum in CDOM, which is in phase with the deepest convection (see Fig. 5), precedes the vernal [Chl]-bloom by about 6-8 weeks. Such a delay between the CDOM peak and the [Chl] peak is obviously not in favor of a fast production of CDOM by the blooming algal standing stock.

A second hypothesis which can also be considered is related to the diminishing solar irradiation during winter. At the subtropical latitudes, the daily photosynthetically available radiation at the surface, $\operatorname{PAR}(0)$, is roughly reduced by a factor 2 in winter, compared to its value in summer; an example for the zone in the vicinity of Easter Island is provided by Fig. 7a. This reduction is not considerable; but, if it is assumed that the phytoplanktonic cells are passively transported by turbulence within the entire extended mixed layer, the radiant energy they receive on average, denoted $\overline{\mathrm{PAR}}$, is much less (see Appendix B for its computation). Actually, the $\overline{\mathrm{PAR}}$ value in winter is reduced by a factor of about 10 compared to its value in summer, as a consequence of the deepening of the mixed layer (Fig. 6c, and Appendix). This reduction in radiant energy may have two consequences, on the [Chl] value, and on the CDOM value. Indeed, it cannot be excluded that an algal photoacclimation process (at low irradiance level) intervenes and results in an increase in chlorophyll cellular content and thus in [Chl], whereas the algal biomass would stay essentially unchanged (see e.g., Winn et al., 1995). According to this scenario, the progressive $[\mathrm{Chl}]$ increase during winter as detected by ocean color imagery would be mainly an effect of photoacclimation. For the same reason, the solar bleaching which affects the CDOM becomes less efficient when exerted upon the entire mixed layer. Therefore unbleached CDOM brought upward by the progressive vertical mixing is able to persist without major damage during the winter period.

The third scenario is simply based on the vertical mixing, which begins in fall when the heat budget becomes negative, and progressively brings upward both unbleached CDOM 
and nutrients (but see Palter et al., 2005). The CDOM pool within the upper layer is thus progressively built up. Thanks to the subsurface delivery of nutrients, phytoplankton may develop. According to the classical scheme, the light limitation, and a lack of stratification at moderate (or high) latitudes, generally prevent algae from growing actively; therefore, the bloom itself is delayed until spring, when light and stability are sufficient. It is postulated here that these limitations (the light level, especially) are less stringent in subtropical zones (the Longhurst's "model 3"), so that the time lag between the CDOM and [Chl] maxima vanishes. In this scheme, the coincidence of the two maxima would not be the straight expression of a causal relationship (i.e., instantaneous CDOM production by developing algae), but the consequence of the same cause (i.e., the convective mixing). This conjecture is supported by the observations of the opposite situation: in absence of efficient vertical mixing (in the site $\mathrm{M}$, especially), [Chl] and the CDOM content stay permanently at their lower level (Table 2 and Fig. 4) and are uncorrelated. Such an explanation involving as the main factor the vertical transport of CDOM is congruent with previous observations (Nelson et al., 1998) showing that CDOM is essentially produced in the subthermocline layer by local heterotrophic processes leading to a remineralization of sinking particulate organic matter. Recent findings (Swan et al., 2009; Nelson et al., 2010) show that this oxidative process in deep waters is reflected by the correlation observed between CDOM and AOU, the apparent oxygen utilization. Less deep, within the subthermocline layer, the production of colored dissolved material is probably related to the average photosynthetic production within the upper well-lit layer which governs the downward vertical flux of materials. Such a link could explain the differences between the sites in terms of average CDOM level (note that this explanation fails in the case of the Sargasso Sea, since [Chl] in the surface layer is low while CDOM is relatively high, as in other parts of the North Atlantic).

The complex interactions regulating the upper layer CDOM concentration were already hypothesized by Siegel et al. (2002, their Fig. 6, for instance). Nevertheless the respective weight of the various processes (local production versus vertical transport, accumulation versus photo-degradation) is largely unknown. The three scenarios above have been independently described for the sake of clarity. It is not only plausible but highly probable that they can coexist. Detailed vertical profiles of both quantities, [Chl] and CDOM, as well as of nutrients and physical/optical conditions, as soon available with profilers (such as Bio-Argo profilers), are needed to get a better understanding of the interwoven processes at play and of their respective contribution.

\section{Appendix A}

A family of curves (numerically a 2-D lookup table) representing the relationship between the ratios $\boldsymbol{R}_{443}^{412}$ and $\boldsymbol{R}_{555}^{490}$ within the $\boldsymbol{R}_{443}^{412}-\boldsymbol{R}_{555}^{490}$ plane is produced when $\Phi$ is given various discrete values around 1 ; these curves form a "grid" which is represented on Fig. 2b in Morel and Gentili (2009a). These computations are made by using the semi-analytical reflectance model described in Morel and Maritorena (2001). When $\Phi$ differs from unity, it is necessary to adopt a spectral dependency for the CDOM absorption, which is, as usual, expressed according to

$a_{\mathrm{y}}(\lambda)=a_{\mathrm{y}}\left(\lambda_{0}\right) \exp \left[-S\left(\lambda-\lambda_{0}\right)\right]$

where $\lambda_{0}$ is a reference wavelength, and $\mathrm{S}\left(\mathrm{nm}^{-1}\right)$ is the exponential decay within the spectral range considered $(412-555 \mathrm{~nm})$. The average slope $\mathrm{S}$ presently adopted is $0.018 \mathrm{~nm}^{-1}$. A sensitivity study with respect to this $S$ value is based on the grids which are obtained when $\mathrm{S}$ is given other plausible values. The same couples of ratios $\boldsymbol{R}_{443}^{412}$ and $\boldsymbol{R}_{555}^{490}$ introduced into these differing grids provide differing $\Phi$ values. Actually they do not differ much: when $\mathrm{S}$ is changed from 0.018 to $0.022 \mathrm{~nm}^{-1}, \Phi$ is diminished by, at the most, $10 \%$ for $\Phi$ between 1 and 2; or, conversely, it is increased by, at the most, $10 \%$ when $\Phi$ is between 1 and 0.5 . These figures are to be inverted for an opposite change in S, from 0.018 to $0.014 \mathrm{~nm}^{-1}$. In the present study, with values never far from unity, the effect of the hypothesis made for $\mathrm{S}$ is largely negligible. The discrepancies on the resulting $\Phi$ values become more important $( \pm 25 \%)$ when $\Phi$ strongly deviates from 1 and approaches values like 0.2 or 5 . These effects are independent of the [Chl] values.

\section{Appendix B}

The average value of the Photosynthetically Available Radiation, denoted $\overline{\text { PAR }}$ within a layer is the average value of the integral of the PAR $(z)$ profile over the layer in question; here the layer considered is the mixed layer of thickness $Z_{\mathrm{ml}}$, so that

$$
\begin{aligned}
& \overline{\mathrm{PAR}}=\left(1 / Z_{\mathrm{ml}}\right) \operatorname{PAR}(0) \int_{0}^{Z \mathrm{ml}} \exp \left(-K_{\mathrm{PAR}} Z\right) d Z \\
& \overline{\mathrm{PAR}} / \operatorname{PAR}(0)=\left(K_{\mathrm{PAR}} Z_{\mathrm{ml}}\right)^{-1}\left[1-\exp \left(-K_{\mathrm{PAR}} Z_{\mathrm{ml}}\right)\right]
\end{aligned}
$$

where $\operatorname{PAR}(0)$ is the PAR value just below surface, $K_{\mathrm{PAR}}$ is the downward attenuation coefficient for PAR. The PAR $(0)$ used here is the daily irradiation (as Einstein $\mathrm{m}^{-2}$ ) derived from the SeaWiFS data; $K_{\mathrm{PAR}}$ can be derived from the $K_{\mathrm{d}}(490)$ the downward attenuation coefficient for the irradiance at $490 \mathrm{~nm}$, or as well from [Chl] (see Eqs. 8 and $9^{\prime}$ in Morel et al., 2007). Such a computation is only an approximation (e.g., $K_{\mathrm{PAR}}$ considered as constant along the depth 
and along the day), but it suffices for what it is intended for. For typical clear waters, with $K_{\mathrm{PAR}} \sim 0.05 \mathrm{~m}^{-1}$, the ratio $\overline{\mathrm{PAR}} / \mathrm{PAR}(0)$ is 0.2 or 0.63 when $Z_{\mathrm{mld}}=100$ or $20 \mathrm{~m}$, respectively. The stronger reduction (by the factor 0.2 ) applies in winter, when $Z_{\mathrm{mld}}$ is maximal and $\operatorname{PAR}(0)$ minimal.

Acknowledgements. The authors would like to thank the NASA SeaWiFS project at the Goddard Space Flight Center, as well as the NASA Ocean Biology Processing Group (OBPG) for maintenance, processing, calibration, and efficient distribution of the SeaWiFS data products, including now the CDOM index. We also want to thank the people involved in the collection of the data which are made freely available by the International Argo Project, a pilot program of the Global Ocean Observing System. This paper represents a contribution to the remOcean project (remotely sensed biogeochemical cycles in the Ocean), funded by the European Research Council. We also are grateful to two anonymous referees for their helpful comments and suggestions.

Edited by: G. Herndl

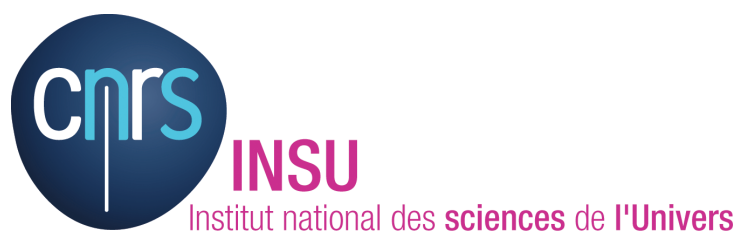

The publication of this article is financed by CNRS-INSU.

\section{References}

Aiken, J., Pradhan, Y., Barlow, R., Lavender, S., Poulton, A., Holligan, P. M., and Hardman-Mountford, N.: Phytoplankton pigments and functional types in the Atlantic Ocean: a decadal assessment, 1995-2005, Deep Sea Res. II, 56, 899-917, 2009.

Antoine, D., André, J.-M., and Morel, A.: Oceanic primary production .2. Estimation at global scale from satellite (coastal zone color scanner) chlorophyll, Global Biogeochem. Cycles, 10, 5769, 1996.

Behrenfeld, M. J., O’Malley, R. T., Siegel, D. A., McClain, C., Sarmiento, J. L., Feldman, G. C., Milligan, A. J., Falkowski, P., Letelier, R. M., and Boss, E. S.: Climate-driven trends in contemporary ocean productivity, Nature, 444, 752-755, 2006.

Boyce, D. G., Lewis, M. R., and Worm, B.: Global phytoplankton decline over the past century, Nature, 446, 591-596, 2010.

Bricaud, A., Babin, M., Claustre, H., Ras, J., and Tièche, F.: Light absorption properties and absorption budget of South East Pacific waters, J. Geophys. Res., 115, C00809, doi:10.1029/2009JC005517, 2010.

Calil, P. H. R. and Richards, K. J.: Transient upwelling hot spots in the oligotrophic North Pacific, J. Geophys. Res., 115, C02003, doi:10.1029/2009JC005360, 2010.

Claustre, H. and Maritorena, S.: The many shades of ocean blue, Science, 302, 1514-1515, 2003.

Claustre, H., Sciandra, A., and Vaulot, D.: Introduction to the special section bio-optical and biogeochemical conditions in the South East Pacific in late 2004: the BIOSOPE program, Biogeosciences, 5, 679-691, doi:10.5194/bg-5-679-2008, 2008. de Boyer Montegut, C., Madec, G., Fisher, A. S., Lazar, A., and Iudicone, D.: Mixed layer depth over the global ocean: An examination of profile data and a profile-based climatology, J. Geophys. Res., 109, C12003, doi:10.1029/2004JC002378, 2004.

Fougnie, B., Henry, P., Morel, A., Antoine, D., and Montagner, F.: Identification and characterization of stable homogeneous oceanic zones: climatology and impact on in-flight calibration of space sensor over Rayleigh scattering, Ocean Optics XVI, Santa Fe, NM, 18-22 November, 2002.

Garver, S. A. and Siegel, D. A.: Inherent optical property inversion of ocean color spectra and its biogeochemical interpretation. 1. Time series from the Sargasso Sea, J. Geophys. Res., 102, 18607-18625, 1997.

Hu, C., Lee, Z., Muller-Karger, F. E., Carder, K. L., and Walsh, J. $\mathrm{J}$.: Ocean color reveals phase shift between marine plants and yellow substance, IEEE Geoscience and remote sensing letters, 3, 262-266, 2006.

Irwin, A. J. and Oliver, M. J.: Are the ocean deserts getting larger?, Geophys. Res. Lett., 36, L18609, doi:10.1029/2009GL039883, 2009.

Longhurst, A.: Seasonal cycles of pelagic production and consumption, Progress in Oceanography, 36, 77-167, 1995.

Maes, C., Ando, K., Delcroix, T., Kessler, W. S., McPhaden, M. J., and Roemmich, D.: Observed correlation of surface salinity, temperature and barrier layer at the eastern edge of the western Pacific warm pool, Geophys. Res. Lett., 33, L06601, doi:10.1029/2005GL024772, 2006.

Maritorena, S., Siegel, D. A., and Peterson, A.: Optimization of a semi-analytical ocean color model for global applications, Appl. Optics, 41, 2705-2714, 2002.

Martinez, E., Antoine, D., d'Ortenzio, F., and Gentili, B.: Climatedriven basin-scale decadal oscillations of oceanic phytoplankton, Science, 326, 1253-1256, 2009.

McClain, C. R., Signorini, S. R., and Christian, J. R.: Subtropical gyre variability observed by ocean-color satellites, Deep Sea Res. II, 51, 281-301, 2004.

Menzel., D. W. and Ryther, J. H.: The annual cycle of primary production in the Sargasso Sea off Bermuda, Deep Sea Res., 6, 115128, 1960.

Menzel, D. W. and Ryther, J. H.: Annual variations in primary production of the Sargasso Sea off Bermuda, Deep Sea Res., 7, 282288, 1961.

Michaels., A. F. and Knap, A. H.: Overview of the US JGOFS BATS and hydrostation S program, Deep Sea Res., 43, 157-198, 1996.

Morel, A. and Maritorena, S.: Bio-optical properties of oceanic waters: A reappraisal, J. Geophys. Res.-Oceans, 106, 7163-7180, 2001.

Morel, A.: Are the empirical laws describing the bio-optical properties of Case 1 waters consistent and internally compatible?, J. Geophys. Res., 114, doi:10.1029/2008JC004803, 2009.

Morel, A., Gentili, B., Claustre, H., Babin, M., Bricaud, A., Ras, J., and Tièche, F.: Optical properties of the "clearest" natural waters, Limnol. Oceanogra., 52, 217-229, 2007a.

Morel, A., Claustre, H., Antoine, D., and Gentili, B.: Natural variability of bio-optical properties in Case 1 waters: attenuation and reflectance within the visible and near-UV spectral domains, as observed in South Pacific and Mediterranean waters, Biogeosciences, 4, 913-925, doi:10.5194/bg-4-913-2007, 2007b. 
Morel, A. and Gentili, B.: A simple band ratio technique to quantify the colored dissolved and detrital organic material from ocean color remotely sensed data, Remote Sens. Environ., 113, 9981011, 2009a.

Morel, A. and Gentili, B.: The dissolved yellow substance and the shades of blue in the Mediterranean Sea, Biogeosciences, 6, 2625-2636, doi:10.5194/bg-6-2625-2009, 2009b.

Nelson, N. B., Siegel, D. A., Carlson, C. A., Swan, C., Smethie Jr., W. M., and Khatiwala, S.: Hydrography of chromophoric dissolved organic matter in the North Atlantic, Deep-Sea Res. I, 54, 710-731, 2007.

Nelson, N. B., Siegel, D. A., Carlson, C. A., and Swan, C.: Tracing global biogeochemical cycles and meridional overturning circulation using chromophoric dissolved organic matter, Geophys. Res. Lett., 37, L03610, doi:10.1029/2009GL04325, 2010.

Omori, Y., Hama, T., Ishii, M., and Saito, S.: Relationship between the seasonal change in fluorescent dissolved organic matter and mixed layer depth in the subtropical western North Pacific, J. Geophys. Res., 115, C06001, doi:10.1029/2009JC005526, 2010.

Palter, J. B., Lozier, M. S., and Barber, R. T.: The effect of advection on the nutrient reservoir in the North Atlantic subtropical gyre, Nature, 437, 687-692, 2005.

Polovina, J. J., Howell, E. A., and Abecassis, M.: Ocean's least productive waters are expanding, Geophys. Res. Lett., 35, LO3618, doi:10.1029/2007GL031745, 2008.

Ras, J., Claustre, H., and Uitz, J.: Spatial variability of phytoplankton pigment distributions in the Subtropical South Pacific Ocean: comparison between in situ and predicted data, Biogeosciences, 5, 353-369, doi:10.5194/bg-5-353-2008, 2008.

Sato, K., Suga, T., and Hanawa, K.: Barrier layer in the North Pacific subtropical gyre, Geophys. Res. Lett., 31, L05301, doi:10.1029/2003GL018590, 2004.

Steinberg, D. K., Carlson, C. A., Bates, N. R., Johnson, R. J., Michaels, A. F., and Knap., A. H.: Overview of the US JGOFS Bermuda Atlantic Time-series Study (BATS): a decade-scale look at ocean biology and biogeochemistry, Deep Sea Res. II, 48, 1405-1447, 2001.

Siegel, D. A., Maritorena, S., Nelson, N. B., Hansell, D. A., and Lorenzi-Kaiser, M.: Global distribution and dynamics of colored dissolved and detrital organic materials, J. Geophys. Res., 107(C12), 3228, doi:10,1029/2001JC000965, 2002.
Siegel, D. A., Maritorena, S., Nelson, N. B., and Behrenfeld, M. J.: Independence and interdependencies among global ocean color properties: Re-assessing the bio-optical assumption, J. Geophys. Res., 110, C07011, doi:10.1029/2004JC002527, 2005a.

Siegel, D. A., Maritorena, S., Nelson, N. B., Behrenfeld, M. J., and McClain, C. R.: Colored dissolved organic matter and its influence on the satellite-based charaterization of the ocean biosphere, Geophys. Res. Lett., 32, L20605, doi:10.1029/2005GL024310, 2005b.

Sverdrup, H. U., Johnson, M. W., and Fleming, R. H.: The oceans, Prentice-Hall, Inc., pp. 1087, 1963.

Swan, C. M., Siegel, D. A., Nelson, N. B., Carlson, C. A., and Nasir, E.: Biogeochemical and hydrographic controls on chromophoric dissolved organic matter distribution in the Pacific Ocean, Deep Sea Res. I, 56, 2175-2192, 2009.

Tomczak, M. and Godfrey, J. S.: Regional Oceanography: an Introduction, Pergamon, pp. 422, 1994.

Wang, M., Knobelspiesse, K. D., and McClain, C. R.: Study of the Sea-Viewing Wide Field-of-view Sensor (SeaWiFS) aerosol optical property data over ocean in combination with the ocean color products, J. Geophys. Res., 110, D10S06, doi:10.1029/2004JD004950, 2005.

Werdell, P. J., Bailey, S. W., Franz, B. A., Morel, A., and McClain, C.: On-orbit vicarious calibration of ocean color sensors using an ocean surface reflectance model, Appl. Optics, 46, 5649-5666, 2007.

Winn, C. D., Campbell, L., Christian, J. R., Letelier, R. M., Hebel, D. V., Dore, J. E., Fujieki, L., and Karl, D. M.: Seasonal variability in the phytoplankton community of the North Pacific subtropical gyre, Global Biogeochem. Cycles,, 9, 605-620, 1995.

Wyrtki., K. and Kilonsky, B.: Mean water and current structure during the Hawaii-to-Tahiti shuttle experiment, J. Phys. Oceanogr., 14, 242-254, 1984.

Yamashita., Y. and Tanoue., E.: Basin scale distribution of chromophoric dissolved organic matter in the Pacific Ocean, Limnol. Oceanogr., 54, 598-609, 2009. 